\title{
Acoustic simulation of J.S. Bach's Thomaskirche in 1723 and 1539
}

\author{
Braxton B. Boren* \\ Audio Technology Program, American University, Washington, 20016 DC, USA
}

Received 19 October 2020, Accepted 29 January 2021

\begin{abstract}
This paper investigates an early acoustical theory of Hope Bagenal about the Leipzig Thomaskirche, where J.S. Bach composed and conducted from 1723 to 1750. Bagenal predicted that the church had a shorter reverberation time than previously in Bach's time as a result of the Lutheran alterations to the space in the 16th century. This study uses on-site measurements to calibrate a geometric acoustical model of the current church. The calibrated model is then altered to account for the state of the church in 1723 and 1539 . Simulations predict that the empty church in 1723 had a T30 value nearly one second lower than today, while the empty church in 1539 was much more reverberant than today. However, when the fully occupied church is simulated across all time periods, the difference in T30 is much smaller, with values at $1 \mathrm{kHz}$ ranging from $2.7 \mathrm{~s}$ in $1539,2.5 \mathrm{~s}$ in the present day, and $2.3 \mathrm{~s}$ in 1723 . These empirical data are crucial for understanding the historical setting of Bach's music as heard by its original congregation and by its composer.
\end{abstract}

Keywords: Room acoustics, Archaeoacoustics, Acoustic simulation, Acoustics of worship spaces, History of acoustics

\section{Introduction}

J.S. Bach (1685-1750) was one of the most influential composers in the Western Classical tradition. Due to its lasting popularity, Bach's work has been the focus of much historical musicological investigation, including the roles of ensemble size [1,2] and period instruments[3-5] in historical performance. Another important factor for understanding the historical effect of Bach's performances is the acoustics of the original performance spaces, as hypothesized by Hope Bagenal in 1930 [6]. Spatial analysis is especially appropriate for Bach, who spent the last 27 years of his life in Leipzig composing music for performance in the Thomaskirche.

Bagenal's analysis of the Thomaskirche's acoustics included the prediction that the space had a lower reverberation time in Bach's day, which would have allowed the composer greater clarity for complex polyphony and dramatic tempo shifts. In addition, Bagenal traced the architectural history of the space back to the changes made after the Lutheran Reformers took over the church in 1539, predicting that the pre-Reformation Catholic church would have been much more reverberant with a corresponding loss in clarity [6, 7]. Lubman and Kiser [8] and Boren [9] have further developed this idea to view worship spaces as a single Acoustic Communication Channel (ACC), through which liturgical practices are optimized to fit their ACC. Though it was not practical to aurally investigate the

*Corresponding author: boren@american.edu change in spaces over time in Bagenal's day, today's computer simulation tools allow us to alter historical room models as easily as historical instruments [10-12].

This study investigates Bagenal's hypothesis via on-site acoustic measurements of the present-day Thomaskirche, which are used to calibrate a geometric acoustic model of the space. The calibrated present-day model is then used as the basis for models of the Thomaskirche in 1723 (when Bach arrived in Leipzig) and 1539 (before the Lutheran alterations). These simulations predict that the Bagenal's general thesis was correct: the reverberation time would have been lower in Bach's era and greater in the pre-reformation space. However, while these differences would have been significant between the empty church in all three time periods, the differences would have been much smaller when the church had a full congregation, which it usually did in Bach's day.

\section{Background}

\subsection{Archaeoacoustics}

The discipline known as "archaeological acoustics" or more commonly "archaeoacoustics" developed out of archaeology as a means to interact with the sound of ancient human sites and artifacts [13, 14]. Early studies examined prehistoric paleolithic caves [15, 16], and as the field expanded more recent historical buildings have been considered $[17,18]$. Originally the field relied mainly on theoretical 
prediction of resonance and reverberation, but over the past 20 years archaeoacoustics has incorporated rigorous procedures for simulation using geometrical acoustics (GA) [19] to investigate historical sound [20-31].

Some early attempts to simulate buildings which no longer exist led to unrealistic GA simulations compared to subjective historical accounts of the building's acoustics [32]. Even if the building's geometrical structure is known, the variation in absorption properties for general categories of materials can lead to large errors in the final simulation due to the multiplicative nature of acoustic reflection and absorption. Because of this concern, studies of the past sound field of buildings which still exist generally use on-site measurements to calibrate a present-day computer model, which can then be altered into a historical model to ensure greater accuracy in the final simulation [33-35].

This study applies the rigorous system for acoustic calibration developed by Postma and Katz [36-38] that accounts for stochastic variation due to the modeling of Lambertian acoustic scattering, which is essential for a realistic GA model [39, 40]. Postma and Katz's calibration method involves running two simulations with all surfaces $0 \%$ scattering and $100 \%$ scattering, respectively, to observe the variation in simulated parameters due to scattering variation alone. After this initial step the initial geometry is held constant while material absorption is incrementally adjusted (within reasonable parameters for each material based on existing measured databases), using acoustic parameters averaged across five GA simulations for each round of calibration until they are within one justnoticeable difference (JND) of the measured value. This procedure was used in the study described below to calibrate a GA model of the Thomaskirche based on measurements taken in the present day structure.

\subsection{History of the Thomaskirche}

Bach's music has been one of the biggest research areas in the Early Music community, including the controversy over the size of his vocal ensembles during normal Sunday cantata performances $[2,41]$. A recent musicological essay arguing that Bach generally had larger vocal ensembles makes general reference to room acoustics and intelligibility [42], but without any quantitative assessment of the acoustics of the Thomaskirche itself. This line of reasoning has some potential toward a better understanding Bach's work, but such an approach requires more specific data about the acoustics of the church in Bach's time.

Bach was an organist and organ installation consultant with decades of experience in carefully listening to the acoustics of different churches [43]. He spent the last 27 years of his life in Leipzig, composing and conducting music in the Thomaskirche. Bach greatly preferred the Thomaskirche over the nearby Nicholaikirche because he deemed it superior for choral music [44]. The combination of Bach's keen ear and his close association with the Thomaskirche make this church one of the most significant performance spaces in the history of Western music.
However, the church has been altered many times, and its current interior is very different from Bach's time [45].

The Thomaskirche is a large late-Gothic church, constructed from 1482-1496, though there was an earlier basilica on the site which dated back to the 12th century $[46,47]$. However, the church was altered after the Lutheran Reformers took over the city of Leipzig in 1539. The Reformers changed most of the service from Latin into the vernacular, which made speech intelligibility a higher priority in their churches. The Lutherans added many seating galleries, reducing the reverberation time, while ensuring clear sight lines from the congregants to the preacher [6]. While many narrative accounts of this transition have emphasized the Reformer's added absorption, a variety of Lutheran bouts of iconoclasm from 1539 to 1541 removed secondary altars around the sides of the nave, which would have added diffusion to the space, as well as the screen separating the chancel from the nave, which would have blocked direct sound from the priests there [48]. In addition, some of the Lutheran galleries functioned as enclosed private seating (similar to opera boxes) surrounded by glass, which may have increased reflection rather than absorption at high frequencies [49]. The current church includes a larger west choir gallery as well as the north and south "Renaissance" galleries added by Hieronymous Lotter in 1570 [46]. The 1539 church featured only a single smaller west choir gallery, which extended only to the first line of columns rather than the second as the current west gallery does (Fig. 1).

While some have emphasized the Lutheran's theology as driving the addition of galleries [50], it was also certainly affected by the larger trend of Leipzig's growing church attendance, which accelerated after the Thirty Years' War (1618-1648) [51]. By Bach's time, the population was large enough that the Thomaskirche often had 2500 seated congregants, with up to another 500 standing on certain occasions [49]. In addition to the galleries present today, the 1723 church also had a double gallery (Fig. 2) made of wood on the north and south, adding additional seating [47]. These double galleries curled around to the north and south ends of the west choir gallery, forming the "Town Piper Galleries" from which most of Bach's instrumental ensemble would perform [52].

It is well known that musicians are greatly affected by the acoustics of the rooms in which their music is performed [53, 54]. For instance, Bach's role model Dietrich Buxtehude composed for the larger church of St. Mary's in Lübeck, where his choir was forced to sing in unison to guide the congregation through the space's long reverberation time [55]. It is therefore worthwhile to investigate the nature of the Thomaskirche's acoustics in Bach's time, as it represents one of the primary acoustic channels through which Bach heard his own music. In addition, we can use historical sources to approximate the acoustics in the pre-Lutheran Thomaskirche to critically investigate Bagenal's hypothesis that the Reformation contributed to Bach's compositional style via its architectural renovations. 


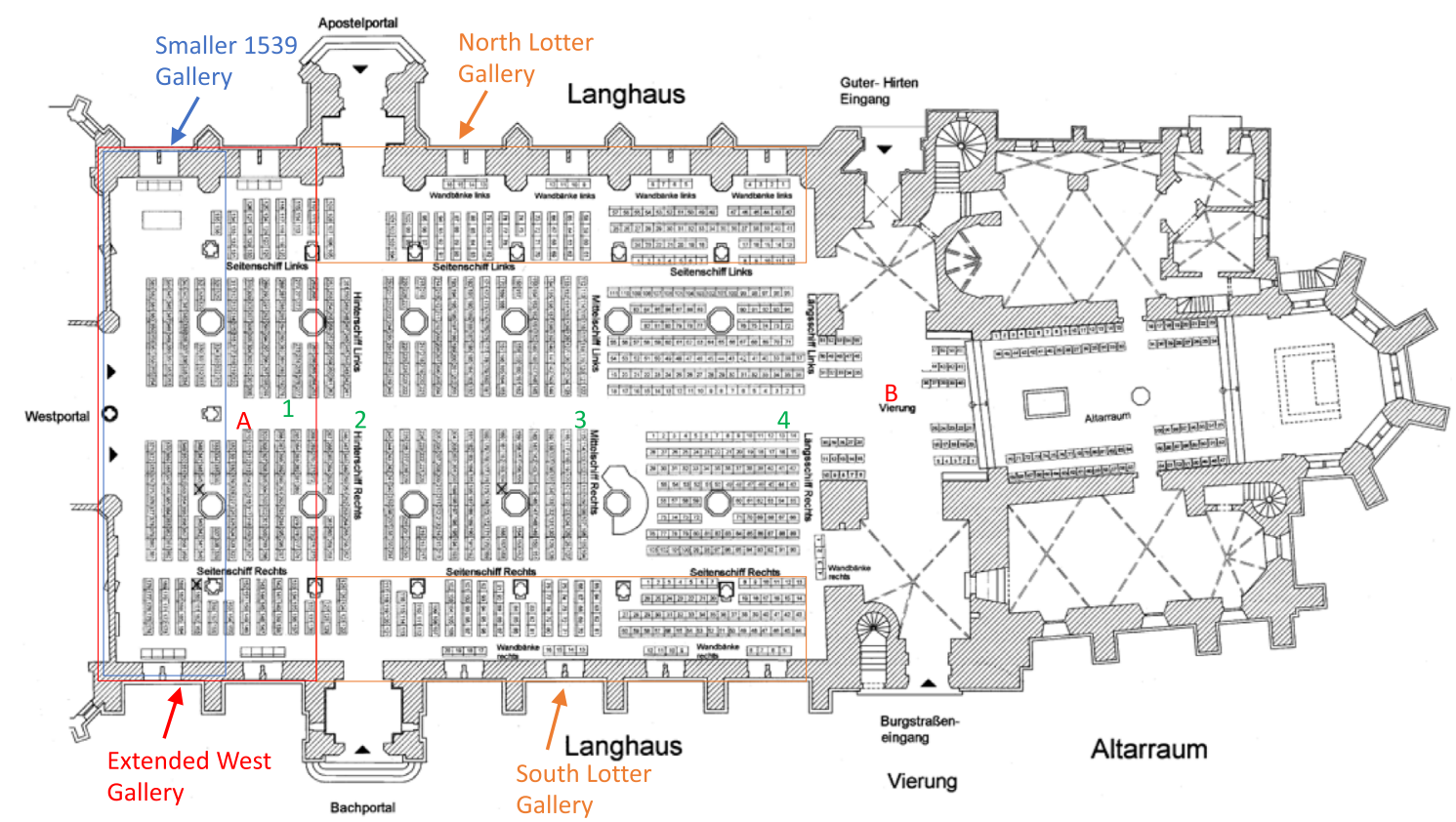

Figure 1. Plan of Thomaskirche with acoustic source (A-B) and receiver (1-4) positions used during on-site measurements.

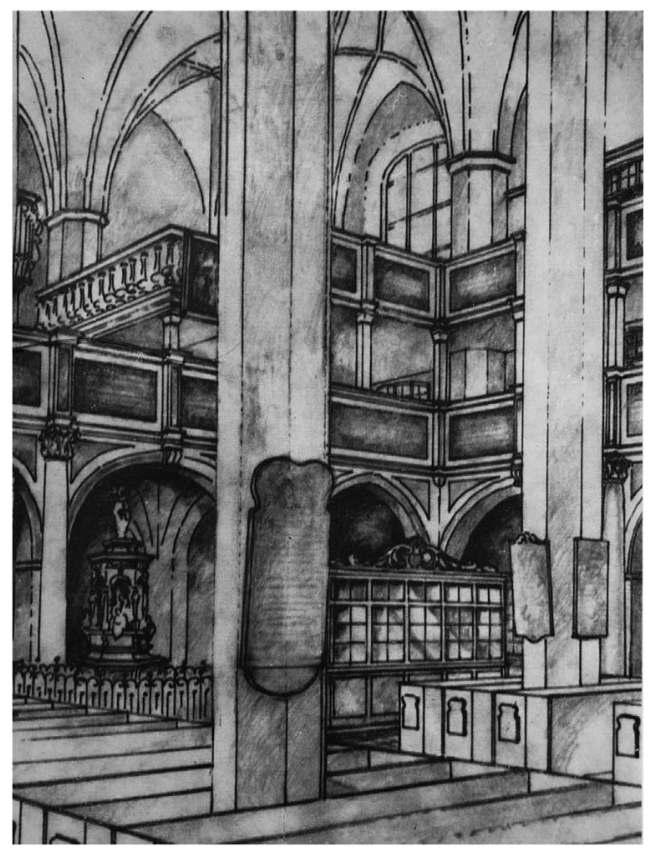

Figure 2. Drawing of Thomaskirche's double gallery in Bach's era [47].

\section{Method}

\subsection{Present day church}

\subsubsection{Acoustic measurements}

The present day Thomaskirche's acoustics were measured using a LookLine DL301 dodecahedral loudspeaker source, which conforms to the omnidirectionality

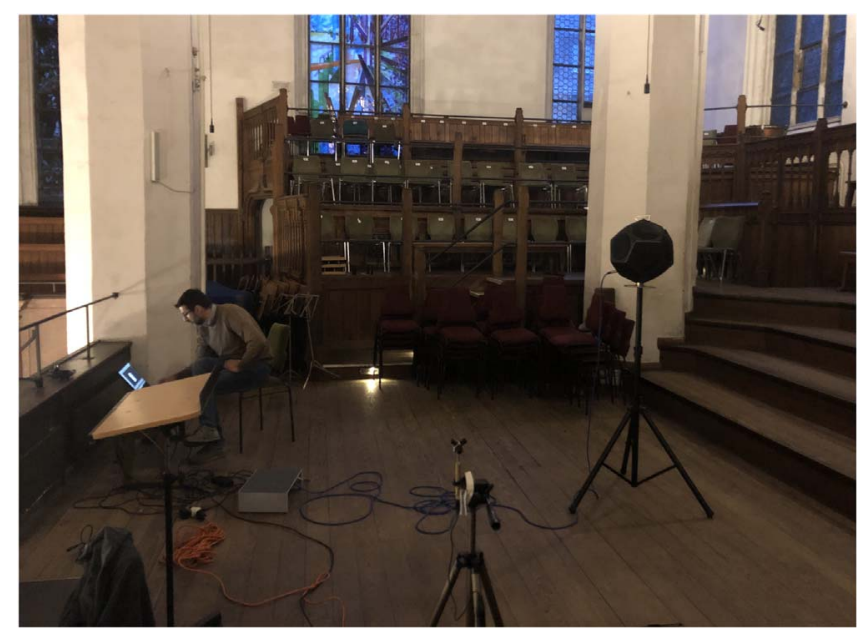

Figure 3. Dodecahedral loudspeaker and TetraMic in the west gallery.

requirements of ISO3382-1, and a CoreSound TetraMic receiver (Fig. 3). Impulse responses were made for two source positions and four receiver positions, marked on the church's plan in Figure 1. Source A approximates the position of the choir in Bach's time, while source B near the chancel in front is used in the present church for smaller ensemble performances. Receiver position 1 was located in the west choir gallery, while positions $2-4$ were located along the main aisle in the nave from west to east.

Acoustic impulses were measured for each sourcereceiver combination (except B-1 because of time restrictions) using an exponential sine sweep test signal [56] recorded and deconvolved using the Aurora room acoustics plug-in within Adobe Audition. While the TetraMic also 


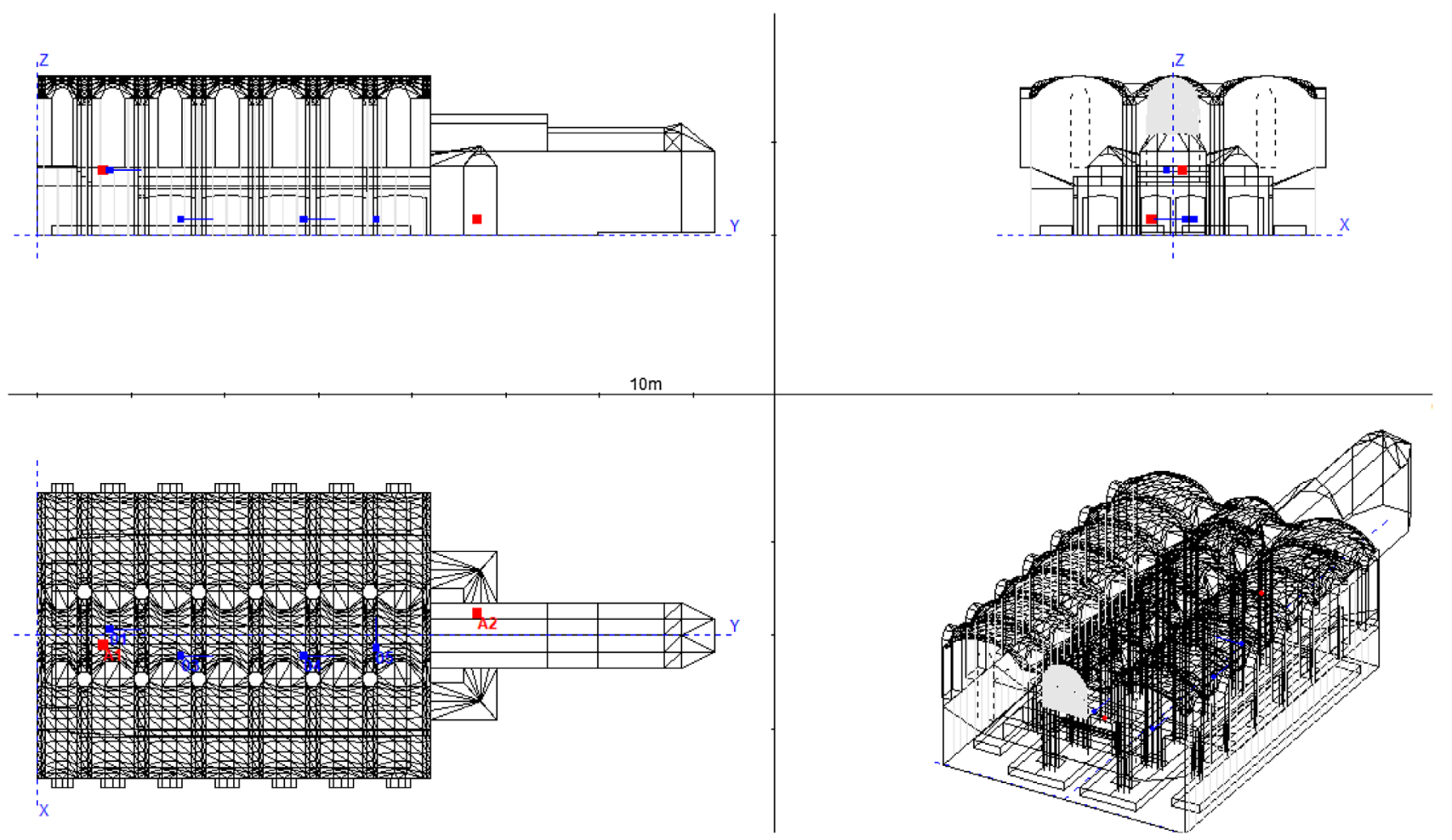

Figure 4. Geometrical model of the Thomaskirche, volume $\approx 16000 \mathrm{~m}^{3}$.

recorded 1st-order Ambisonic impulse responses, the acoustic metrics used in this study only require the 0th-order (omnidirectional) response for each receiver position. From these impulse responses standard room acoustics metrics (T30, T20, EDT, C80, $T_{s}$, etc.) were computed using Aurora for octave bands from 125 to $8000 \mathrm{~Hz}$.

\subsubsection{Model calibration}

The present day church was modeled geometrically (Fig. 4) in CATT-Acoustic v.9.1b [57, 58], with acoustic simulation via CATT's The Universal Cone Tracer v2.0 (TUCT2). TUCT2 contains three different GA algorithms for acoustic cone tracing: algorithm 1 is fastest but contains some stochastic processes for modeling scattering, while algorithms 2 and 3 are deterministic but have much longer computation times than algorithm 1 . Because the space is acoustically mixing, it was determined (following [37]) to use the averaged values from five runs of algorithm 1 for each round of calibration, as this still reduced computation time significantly compared to using either of the deterministic algorithms. Each simulation used TUCT2's recommended value of 99927 cones based on the church's internal volume $\left(\approx 16000 \mathrm{~m}^{3}\right)$, with an impulse response length of $4500 \mathrm{~ms}$, slightly longer than the longest T30 value measured in the space. The air absorption settings in CATT were defined based on a temperature of $16{ }^{\circ} \mathrm{C}$ and $80 \%$ atmospheric humidity, based on the atmospheric values present during the acoustic measurements.

According to the calibration procedure defined in $[37,59]$, the church geometry was held constant throughout.
Initial absorption coefficients were assigned to all materials based on existing databases in CATT, with scattering coefficients generally assigned based on a characteristic depth value, which represents the average depth variation in a single material which may represent a more complex surface in the physical church. This method allows a more intuitive relationship between physical characteristics and acoustic scattering, for which measured values may not be available. CATT calculates the scattering coefficient for the frequency band centered at $f$ according to Equation (1):

$$
\left.\operatorname{scatt}(f)\right|_{\geq 0.10} ^{\leq 0.99}=0.5 \sqrt{\frac{d}{\lambda}},
$$

where $d$ is the characteristic depth and $\lambda$ is the wavelength of $f$.

At the beginning of the calibration procedure, two observational simulations were also conducted with all surfaces $0 \%$ and $100 \%$ scattering, respectively, to observe the variation in acoustic metrics due to scattering alone. After this initial step, the absorption and characteristic depth were gradually calibrated over 19 rounds of 5 simulations each, with the goal of simulating T30 within 5\% (or 1 JND) of measured values for octave bands 250-2000 Hz. Final absorption coefficients and characteristic depth are given in Table 1. Surfaces with characteristic depth marked $\S$ have scattering coefficients defined by frequency band, given in Table 2. The organ pipes were defined as a 1D diffusor along the vertical dimension within CATT, which focuses their scattering along the horizontal plane. Complex woodworking (like the organ bench) which could not be modeled 
Table 1. Calibrated absorption coefficients and characteristic depth by octave band center frequency (Hz) for surfaces in the Thomaskirche GA model.

\begin{tabular}{|c|c|c|c|c|c|c|c|}
\hline Surface & 125 & 250 & 500 & 1000 & 2000 & 4000 & Characteristic depth (m) \\
\hline Organ pipes & 0.35 & 0.35 & 0.20 & 0.20 & 0.30 & 0.25 & $\S$ \\
\hline Complex wood surfaces & 0.12 & 0.19 & 0.08 & 0.07 & 0.05 & 0.04 & 0.5 \\
\hline Smooth wood surfaces & 0.12 & 0.19 & 0.08 & 0.07 & 0.05 & 0.04 & 0.02 \\
\hline Tile floor & 0.03 & 0.02 & 0.02 & 0.02 & 0.03 & 0.03 & 0.1 \\
\hline Painted plaster ceiling & 0.08 & 0.10 & 0.13 & 0.09 & 0.12 & 0.18 & 0.1 \\
\hline Pillars & 0.11 & 0.12 & 0.05 & 0.04 & 0.04 & 0.06 & 0.02 \\
\hline Plaster walls & 0.09 & 0.11 & 0.05 & 0.04 & 0.04 & 0.04 & 0 \\
\hline Complex walls & 0.09 & 0.11 & 0.05 & 0.04 & 0.04 & 0.04 & 1.0 \\
\hline Chancel walls (primarily plaster) & 0.14 & 0.07 & 0.02 & 0.02 & 0.01 & 0.06 & 0.1 \\
\hline Portal walls (primarily plaster) & 0.14 & 0.07 & 0.02 & 0.02 & 0.01 & 0.06 & 0.05 \\
\hline
\end{tabular}

Table 2. Scattering coefficients by octave band center frequency (Hz) for specified surfaces in the model.

\begin{tabular}{lccccc}
\hline Surface & 125 & 250 & 500 & 1000 & 2000 \\
\hline Empty pews [58] & 0.30 & 0.40 & 0.50 & 0.60 & 0.70 \\
Organ pipes [69] & 0.20 & 0.30 & 0.40 & 0.50 & 0.80 \\
\hline
\end{tabular}

precisely was given the same absorption coefficients as smooth wood but a much higher characteristic depth to account for scattering from geometrical elements not present in the simplified GA model. The walls of the portals and chancel are made primarily of plaster, but have varying amounts of paintings and ornamentation hung on them, so these were modeled with the same absorption but different characteristic depths. The floor of the west gallery was given a small amount of sound transmission in the low frequency bands (Table 3), which improved the accuracy in $\mathrm{C} 80$ at position $\mathrm{A} 2$.

The church's mid-frequency T30 was about 4s, similar to that measured before the church's renovations in the 1960s [60]. After calibration all T30 values were within 1 JND with the exception of the $500 \mathrm{~Hz}$ band for A2 and B2 (Figs. 5 and 6). For these positions the simulated T30 for A2 was slightly too high, while the value at B2 was slightly too low. These were not able to be calibrated with 1 JND without assuming unreasonable absorption values for nearby surfaces and/or splitting homogeneous surfaces into sections with different material properties. Since this risks overfitting the model to individual data points, it was decided that the model was better with reasonable materials that more accurately represented the surfaces present in the Thomaskirche.

Though reverberation time (here represented by T30) was the main thrust of Bagenal's hypothesis, other more position-specific acoustic metrics, such as C80, EDT, and $T_{s}$ were also used during calibration. In addition to the calibration goals for T30, C80 was used particularly with the goal of getting pointwise simulations within $3 \mathrm{~dB}$ (or 2 JNDs [61]) of measured values for the same frequency range $(250-2000 \mathrm{~Hz})$ as T30. Most of the frequency bands were within this range, such as a fairly straightforward impulse response from source B to receiver 4 (Fig. 7). In contrast, C80 from source A to receiver 2 was simulated significantly lower than measured values. Again, the error could be ameliorated somewhat, but only by choosing unreasonable absorption values or splitting single materials into multiple different sections with different acoustic properties. However, since there is no direct sound path from A to receiver 2, it was decided that this result was good enough, particularly since TUCT's GA simulations only approximate acoustic diffraction [62], and there was likely a stronger early sound component diffracting around the choir gallery resulting in the larger measured value. Since this will be the case in all GA simulations to follow, some care must be used in predictions underneath the main galleries with no direct line of sight to a sound source.

\subsection{3 model}

The Thomaskirche has undergone multiple sets of renovations since the Lutheran iconoclasms in the 16th century. Since Bach's time it was dramatically altered in the 19th and 20th centuries before the 1960s renovations which sought to restore a visual aesthetic more similar to that of Bach's era. Though there are not many visual renderings of the church in Bach's time, the descriptions in [46-48] as well as the reconstructed images from Christoph Wolff's work [52] served as a basis for altering the calibrated present-day model into a model of the Thomaskirche as it 
Table 3. Sound transmission coefficients by octave band center frequency $(\mathrm{Hz})$ for specified surfaces in the model.

\begin{tabular}{lcccccc}
\hline Surface & 125 & 250 & 500 & 1000 & 2000 & 4000 \\
\hline Gallery floor & 0.20 & 0.10 & 0.10 & 0.01 & 0.01 & 0.01 \\
\hline
\end{tabular}
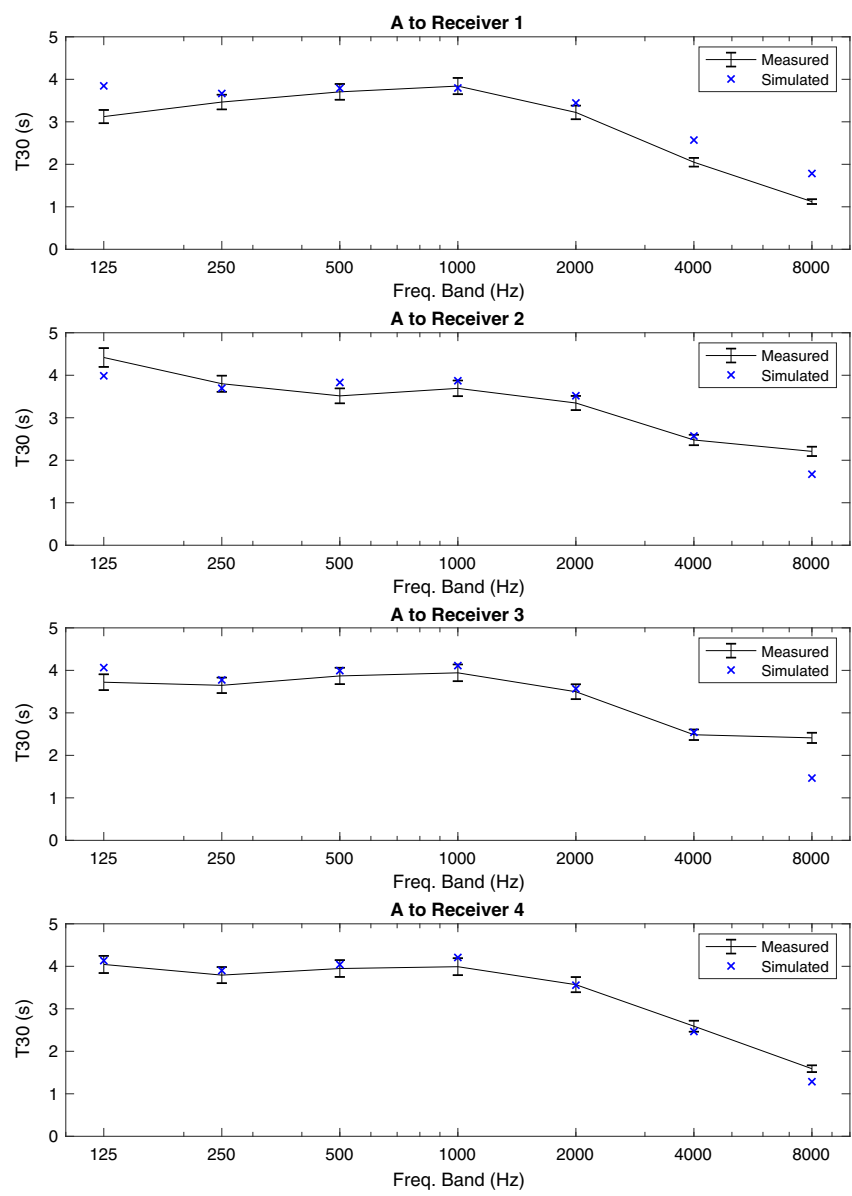

Figure 5. T30 simulations versus measurements from source position A (Error bars $= \pm 1 \mathrm{JND})$.

existed in 1723, when Bach took up his post as Thomaskantor (Fig. 8). In particular, a higher wooden gallery with wooden seating was added above the present Lotter galleries on the north and south, curling around to form the "Town Piper" galleries above the present west choir gallery. Several boxes of pews, enclosed by glass, were added, using the same absorption and scattering properties as the glass windows in the rest of the church. The main organ's pipe layout was based on Wolff's rendering in [52], as the current organ does not date to Bach's time. Finally, the second "Swallow's Nest" organ above the chancel was added, which no longer exists.

In addition to the acoustic analysis of the space, the model was also used to simulate binaural impulse responses from virtual source and receiver positions in the piper galleries, the choir gallery, and both organs, to conduct a virtual recording session in the 1723 church, described in
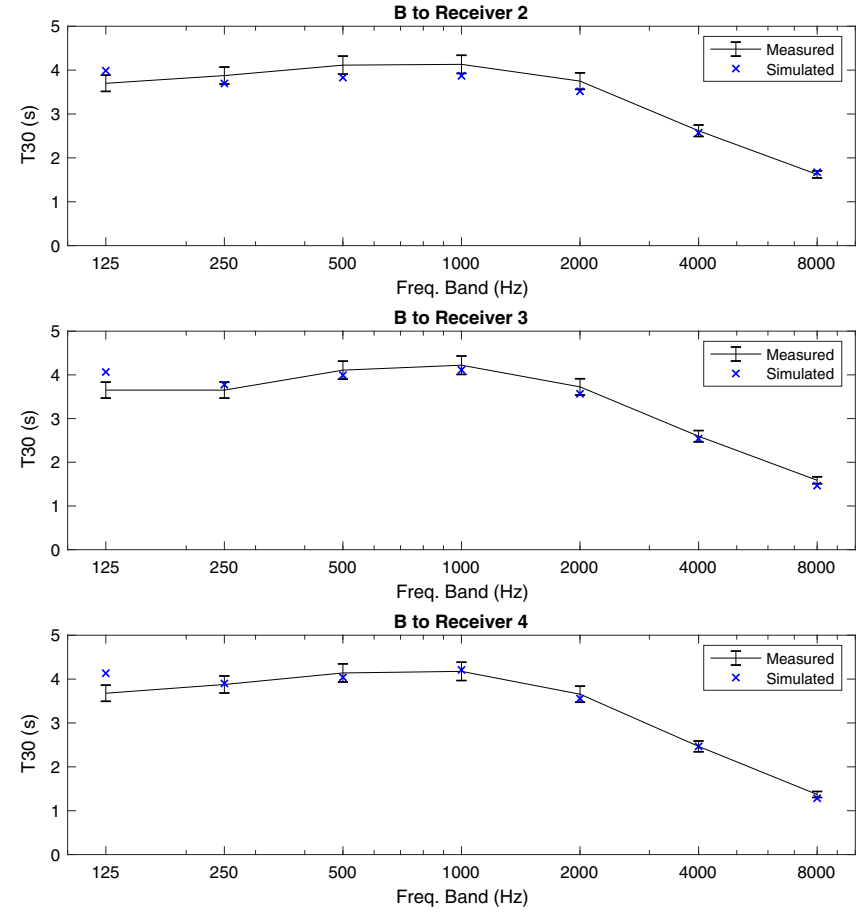

Figure 6. T30 simulations versus measurements from source position B (Error bars $= \pm 1$ JND).

a separate manuscript [63]. For the purposes of the present study, analysis will be limited to the receiver positions measured in the present-day church.

\subsection{9 model}

The calibrated present-day model was also altered to account for the church's layout in 1539, on the eve of the Reformation's arrival. Though less detailed information is available for this era, the following main points [48] are known:

- There were no galleries on the north and south of the nave.

- The west gallery was half the size of the current west choir gallery.

- Various altars existed along the side of the the nave for personal devotions.

- A rood screen divided the chancel from the nave.

These four changes were all implemented in the GA model, removing the Lotter galleries and halving the size of the west gallery. Though the exact nature of the side altars is not known, altars were added as highly scattering marble rectangular prisms, based on side altars in Catholic churches $[64,65]$. The rood screen was modeled as highly scattering marble and made partially acoustically transparent, based on other European rood screens from the period [66]. The absorption coefficients and characteristic depth for these surfaces are given in Table 4, and the sound transmission coefficients for the rood screen are given in Table 5 . 

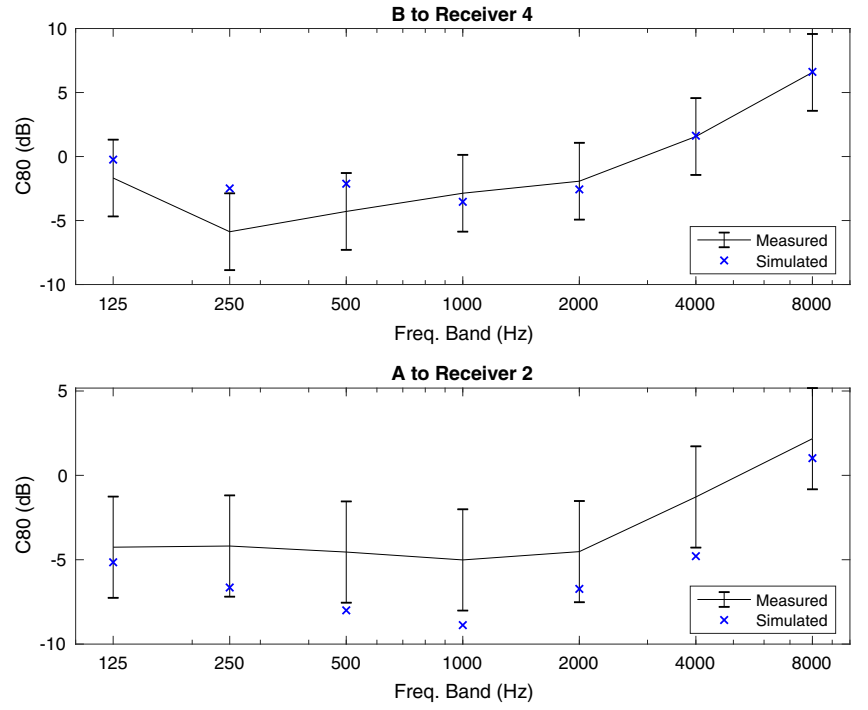

Figure 7. C80 simulations versus measurements for positions B4 and A2 (Error bars $= \pm 2$ JND).

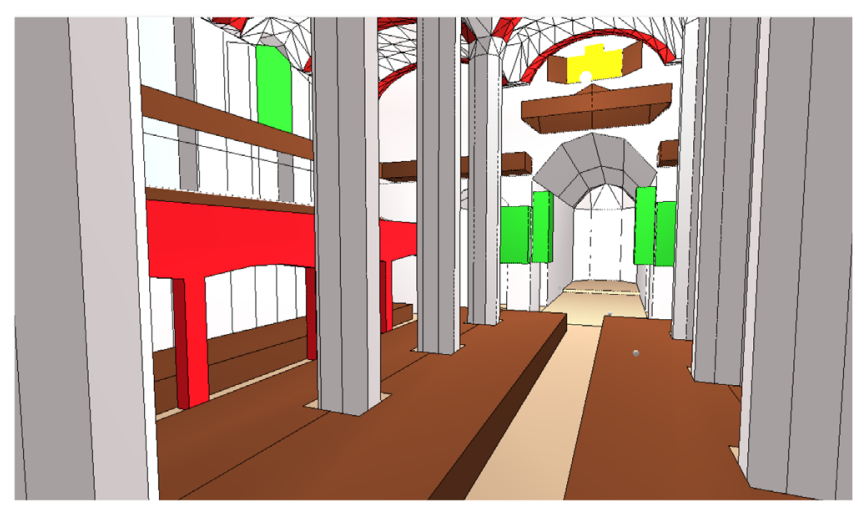

Figure 8. Model of the Thomaskirche in 1723, including second wooden gallery, glass pew enclosures (in green) and the "swallow's nest" organ (in yellow).

\subsection{Empty church comparisons}

Using the altered GA models for the 1723 and 1539 churches, both past models were simulated in TUCT2 using the same parameters (five runs using algorithm 1, 99927 cones, $16{ }^{\circ} \mathrm{C}, 80 \%$ humidity) as for the present-day church. Initial trial runs with very long impulse responses were simulated first to approximate the longest T30 value in each space, which was used to set the impulse response length during the final runs: $4500 \mathrm{~ms}$ for the 1723 church (same as present day) and $5800 \mathrm{~ms}$ for the 1539 church.

Based on these parameters, the acoustic metrics for each source-receiver combination were averaged across all five runs for each time period. Figure 9 shows the simulated T30 for the 1539, 1723, and present day space under empty conditions for source A, spatially averaged across all receiver positions. The 1723 church was found to have a T30 of about $3.5 \mathrm{~s}$ at $1 \mathrm{kHz}$, about half a second lower than the present day church. The 1539 church, however, had
T30 values about 1 s higher than present day values in the same frequency band.

\subsection{Full church comparisons}

In addition to analyzing the empty church, which was able to be measured, it is also important to consider the church when fully occupied, as it would have been during the performance of Bach's cantatas and passions [49]. To investigate this effect, three additional models were created: one for each era with full occupancy. For this purpose two more surfaces were introduced: full-occupancy pews and medium-density crowds, whose absorption coefficients are given in Table 6 . The full pews were substituted for the top side of all previously empty pews, and the crowd was substituted for the floor area in the galleries where the choir and orchestra would have been. According to the recommendations in [37, 58], scattering coefficients for both surfaces were given by the values in the CATT Surface Properties module, beginning at $30 \%$ at $125 \mathrm{~Hz}$ and increasing by $10 \%$ per octave band up to a maximum value of $70 \%$.

With these changes made, all three "full church" models were simulated, again taking the average acoustic parameters across five runs using algorithm 1 in TUCT2. The spatially averaged T30 from source A by octave band for each era is shown in Figure 10. As would be expected, the T30 values were much smaller in all three cases, but the difference between each model was also decreased: at $1000 \mathrm{~Hz}$ the 1539 church still had the greatest T30 at about $2.7 \mathrm{~s}$, but the respective values for the present day church and the 1723 church were $2.5 \mathrm{~s}$ and $2.3 \mathrm{~s}$. This compression of T30 values in the full church model held across all positions for the three eras. In addition, the low-frequency T30 was nearly the same between the present-day and 1723 churches. Table 7 shows the spatially averaged T30 from Source A and standard deviations for all six configurations of the GA model.

\section{Discussion}

Bach scholar C.S. Terry, responding to Bagenal's paper on the Thomaskirche, claimed that "The Reformation intimately affected church acoustics." [50] Bagenal himself went a bit further, concluding that:

[the Lutheran addition of galleries] created the acoustic conditions that made possible the seventeenth century development of cantata and Passion. The building became, in fact, a kind of religious opera house [6].

To evaluate these broader statements about the acoustic significance of the Reformation, we ought to keep in mind the difference between the empty and occupied states of the church. In all eras, Bach's (1723) Thomaskirche was drier than today, and the pre-Lutheran church had a longer reverberation time than today. However, the gap between those eras is large for the empty church (more than $2 \mathrm{~s}$ in 
Table 4. Absorption coefficients and characteristic depth by octave band center frequency (Hz) for additional surfaces in the 1539 Thomaskirche GA model.

\begin{tabular}{lccccccc}
\hline Surface & 125 & 250 & 500 & 1000 & 2000 & 4000 & Characteristic depth (m) \\
\hline Marble altar & 0.01 & 0.01 & 0.01 & 0.01 & 0.02 & 0.02 & 0.5 \\
Screen & 0.01 & 0.01 & 0.01 & 0.01 & 0.02 & 0.02 & 0.5 \\
\hline
\end{tabular}

Table 5. Sound transmission coefficients by octave band center frequency $(\mathrm{Hz})$ for specified surfaces in the 1539 model.

\begin{tabular}{lcccccc}
\hline Surface & 125 & 250 & 500 & 1000 & 2000 & 4000 \\
\hline Screen & 0.20 & 0.20 & 0.10 & 0.10 & 0.10 & 0.10 \\
\hline
\end{tabular}

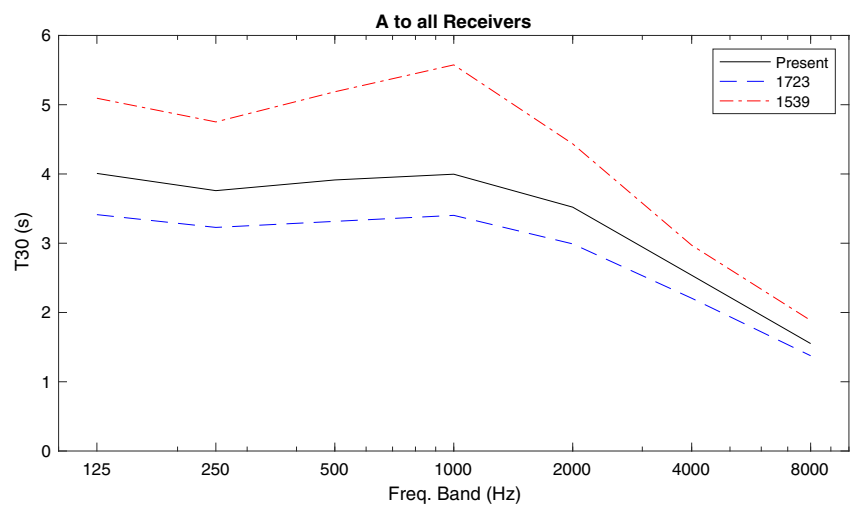

Figure 9. Simulated T30 for empty Thomaskirche in all three eras, from source A, spatially averaged.

the $1000 \mathrm{~Hz}$ band between 1539 and 1723) while it is much lower when the church is occupied (about 0.4s). While Bach's ensemble probably rehearsed in the empty church from time to time, the premieres of his cantatas and passions occurred during the Sunday service, when the church would have been full. Professional musicians today intuitively understand the difference between empty and full performance conditions, especially in un-upholstered settings like churches. Though we do not have documentary evidence of Bach speaking directly to this question, one imagines that, based on the description of him listening carefully to spaces when inspecting organs, he would have grasped this difference and perhaps have cautioned his young choristers to be careful of their tempo during the Sunday service.

The additional 500 standing persons reported at the larger occasions [49] were not simulated here, as this project was primarily focused Bach's cantatas [63]. However, the standing room was located under the overhanging west choir gallery, so the additional absorption may not have affected the reverberation equally throughout the volume in any case. As would be expected, C80 in these simulations was inversely correlated with T30, with the gaps between different eras also much smaller in the occupied church. Therefore Bach's congregation would have experienced slightly higher clarity, but the difference between 1723 and the present day would be small when the church was fully occupied. Since C80 is a more useful metric for specific
Table 6. Absorption coefficients by octave band center frequency $(\mathrm{Hz})$ for additional surfaces in the full-occupancy Thomaskirche GA models.

\begin{tabular}{lcccccc}
\hline Surface & 125 & 250 & 500 & 1000 & 2000 & 4000 \\
\hline Wooden pews, & 0.57 & 0.61 & 0.75 & 0.86 & 0.91 & 0.86 \\
100\% occupancy [70] & & & & & & \\
$\begin{array}{l}\text { Audience area, } \\
0.72 \text { persons } / \mathrm{m}^{2}[71]\end{array}$ & 0.10 & 0.21 & 0.41 & 0.65 & 0.75 & 0.71 \\
\hline
\end{tabular}

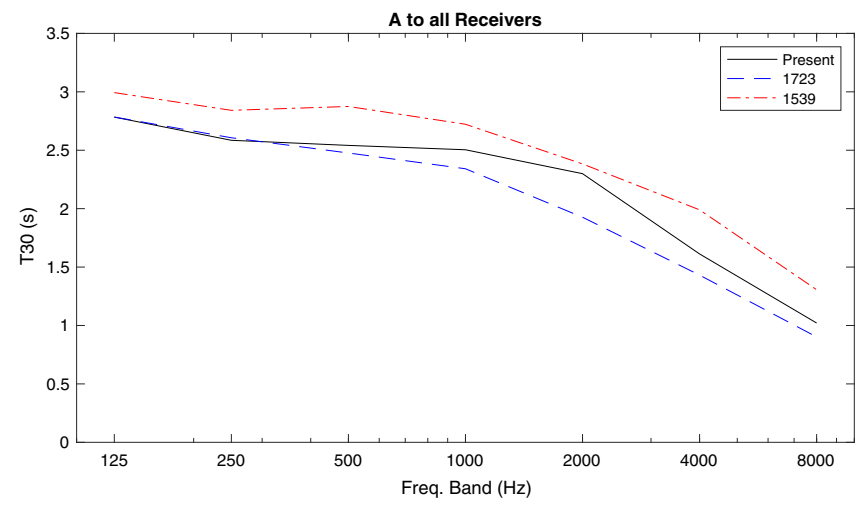

Figure 10. Simulated T30 for fully occupied Thomaskirche in all three eras, from source A, spatially averaged.

source-receiver combinations, it will be used more in future work examining of the exact acoustic paths in the 1723 church between specific instrument groups Bach used on different occasions.

While the difference between the occupied Thomaskirche of 1539 and 1723 is still significant relative to a present-day concert hall, it is not a drastic, physical manifestation of Lutheran theology that allowed Bach the acoustic clarity to realize his most complex compositional ideas. However, we can say that, even when occupied, the 1723 church would have had a reverberation time near the upper threshold of that considered desirable in a concert hall today. The greatest reason for this is, as Bagenal predicted, the two sets of galleries, which add significant absorption even when empty. Some questions remain, such as the exact type of glass used to enclose the private box seats in Bach's day, or the geometry of the altars that were removed from the church during the Lutheran iconoclasms. Changes to these inputs could plausibly result in small changes in the projected T30 values reported here.

Previous scholars have examined the role of Lutheran theology in Bach's life [67], but in evaluating the role of the Reformation on acoustics, we must be careful in defining the counterfactual which we are evaluating: if Bach 
Table 7. Simulated spatially averaged T30 (s) from source A by octave band in all eras for the empty and full-occupancy Thomaskirche GA models.

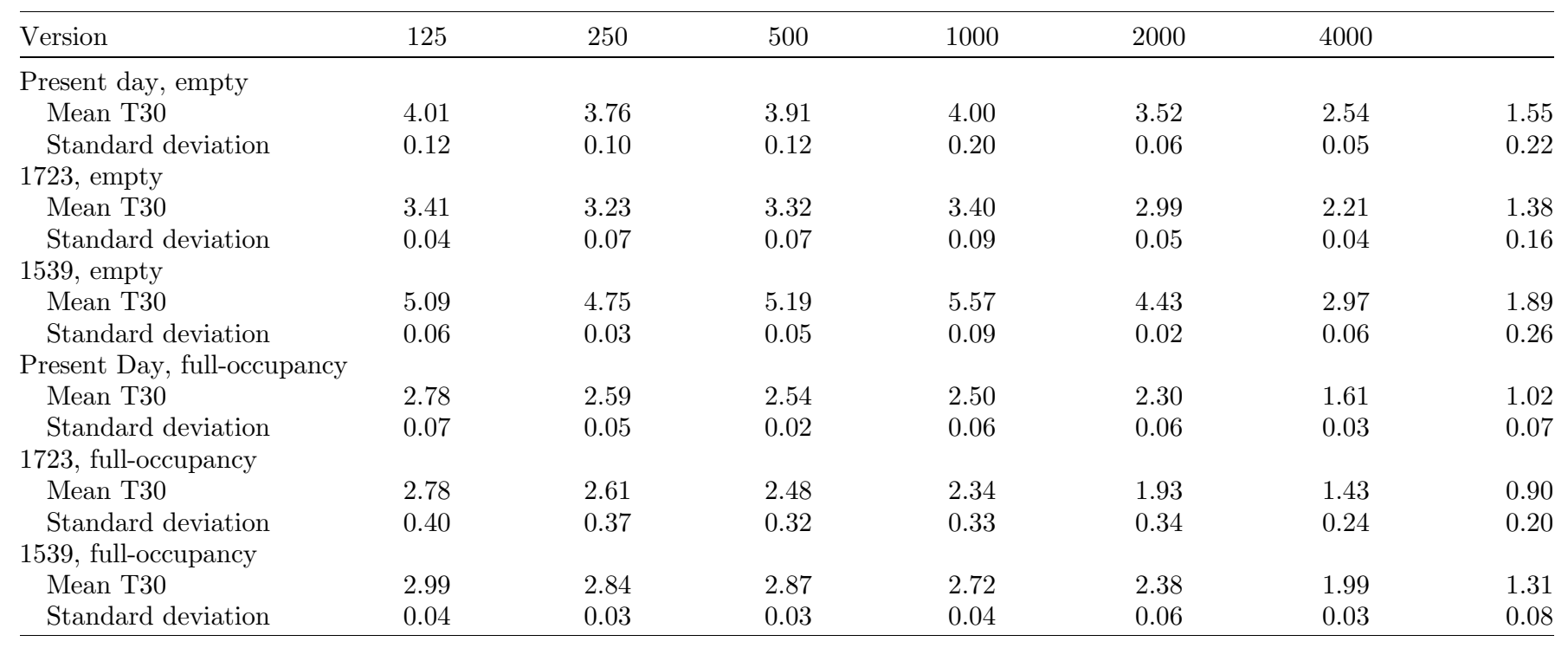

had become Thomaskantor in the 1539 church, still Catholic, in which no Reformation had taken place and the population of Leipzig had stayed the same, presumably he would have inherited a slightly more reverberant space. But given the various demographic shifts occurring in Germany throughout the 16th century [68], one imagines that a Catholic Thomaskirche would probably have increased its seating capacity by 1723 as well. Tanya Kevorkian's research [49] has uncovered many instances of complaints about noise from the congregants during the cantata performance, which also complicates any attempt to make a definitive claim about the clarity of Bach's music for its original listeners. Since such humanproduced noises are less regular and predictable than mechanical noise sources today, the ultimate clarity of Bach's original performances likewise must have varied somewhat from week to week [51].

\section{Conclusion and future work}

The Leipzig Thomaskirche has undergone many changes since its creation and since Bach served as cantor there. The GA models used here, calibrated based on the present-day church, help to illustrate the acoustic differences between the church before the Reformation, in Bach's day, and in the present. The 1723 church, with its double galleries, has the lowest reverberation time, while the 1539 church had almost no galleries and a high reverberation time when empty. The current church's T30 is between these two extremes, as the space has only one set of side galleries.

However, when a full congregation is simulated in these models, the ordering of their T30 values stays the same but the difference is greatly compressed. Since Bach's cantatas were performed in a full church nearly every Sunday, we should not assume that the Reformation created a qualitatively different acoustic experience: rather, at most we can say that the reverberation time was slightly lower than today, depending on the occupancy of the church.

In the future, the $1723 \mathrm{GA}$ model of the Thomaskirche will be used to create immersive simulations of different musicological hypotheses about the usual size and makeup of Bach's performing forces. Using directivity data and maximum SPLs for each instrument, it is possible to evaluate the balance between the instrumental ensemble and Bach's choral ensemble, which may help provide some new data in the ongoing debate about the size of Bach's chorus $[41,42]$. If acoustical analysis suggests that a 4 -voice choir definitely could (or definitely could not) be heard over Bach's instrumental ensemble, computer modeling can help introduce more empirical evidence into the musicological debate. Finally, the model will allow us to virtually sit next to Bach in the galleries and hear one of his cantatas (approximately) as he would have heard it himself.

\section{Acknowledgments}

This research was funded by United States National Endowment for the Humanities' Digital Humanities grant award number A19-0069-001, "Hearing Bach's Music as Bach Heard It." The author would like to thank the Leipzig Bach-Archiv for their assistance in accessing some obscure architectural records. Thanks to Rev. Britta Taddiken for access to the Thomaskirche for physical and acoustic measurements. Thanks to Jackson Anthony for assistance in translation of many of the German texts, Elizabeth Grzyb for help in the geometrical modeling of the church, and Davide Bonsi for assistance during the acoustic measurement of the Thomaskirche. Thanks also to Daniel Abraham, Tanya Kevorkian, Markus Rathey, 
Christoph Wolff, and Markus Zepf for their expertise on the architectural and musical history of the Thomaskirche. Final thanks to Brian Katz for his productive comments about the calibration process for the GA model.

\section{References}

1.A. Parrott: The Essential Bach Choir. Boydell Press, Woodbridge, UK, 2000.

2. J. Rifkin: Bach's Chorus. The Musical Times 123, 1677 (1982) 747-751, 753-754.

3. J. Butt: Playing with History: The Historical Approach to Musical Performance. Cambridge University Press, Cambridge, UK, 2002.

4. R. Donington: The choice of instruments in baroque music. Early Music 1, 3 (1973) 131-138.

5. H. Gotlieb, V.J. Konečni: The effects of instrumentation, playing style, and structure in the goldberg variations by Johann Sebastian Bach. Music Perception 3, 1 (1985) 87-102.

6. H. Bagenal: Bach's music and church acoustics. Music and Letters 11, 2 (1930) 146-155.

7. H. Bagenal: Planning for Good Acoustics. E.P. Dutton and Co., New York, NY, 1931.

8. D. Lubman, B.H. Kiser: The history of western civilization told through the acoustics of its worship spaces, in Proceedings of the 17th International Congress on Acoustics, Rome, Italy. 2001.

9. B.B. Boren: A generalized version of the Lubman-Kiser theory of historical acoustics and worship spaces. Journal of the Acoustical Society of America 141 (2017) 3774.

10.B.B. Boren: Computational acoustic musicology. Digital Scholarship in the Humanities 34, 4 (2019) 707-715.

11. J. Rindel: The use of computer modeling in room acoustics. Journal of Vibroengineering 3, 4 (2000) 219-224.

12. S. Siltanen, T. Lokki, L. Savioja: Rays or waves? Understanding the strengths and weaknesses of computational room acoustics modeling techniques, in Proceedings of the International Symposium on Room Acoustics, Melbourne, Australia. 2010.

13. S.-A. Goh: Sonic Knowledge Production in Archaeoacoustics: Echoes of elsewhere? PhD thesis, University of London, Goldsmiths, 2020.

14. C. Scarre, G. Lawson, Editors: Archaeoacoustics. McDonald Institute for Archaeological Research, Cambridge, UK, 2006.

15. R.G. Jahn: Acoustical resonances of assorted ancient structures. Journal of the Acoustical Society of America 99, 2 (1996) 649-658.

16. I. Reznikoff: Sound resonance in prehistoric times: A study of Paleolithic painted caves and rocks, in Acoustics '08, Paris. 2008, pp. 4137-4141.

17. B.B. Boren: History of 3D sound, in Immersive Sound: The Art and Science of Binaural and Multi-Channel Audio, Roginska A, Geluso P, Editors, Focal Press, New York, NY. 2017.

18. R. Suárez, J.J. Sendra, A. Alonso: Acoustics, liturgy and architecture in the early Christian church. from the domus ecclesiae to the basilica. Acta Acustica United with Acustica 99, 2 (2013) 292-301.

19. L. Savioja, U. Peter Svensson: Overview of geometrical room acoustic modeling techniques. Journal of the Acoustical Society of America 138, 2 (2015) 708-730.

20. J. Abel, J. Rick, P. Huang, M. Kolar, J. Smith, J. Chowning: On the acoustics of the underground galleries of Ancient Chavin de Huantar, Peru, in Acoustics '08, Paris. 2008.
21. A. Alonso, R. Suárez, J.J. Sendra: Virtual reconstruction of indoor acoustics in cathedrals: The case of the Cathedral of Granada. Building Simulation 10, 4 (2017) 431-446.

22. L. Álvarez-Morales, F. Martellotta: A geometrical acoustic simulation of the effect of occupancy and source position in historical churches. Applied Acoustics 91 (2015) 47-58.

23. L. Álvarez-Morales, T. Zamarreño, S. Girón, M. Galindo: A methodology for the study of the acoustic environment of Catholic cathedrals: Application to the Cathedral of Malaga. Building and Environment 72 (2014) 102-115.

24. D. Bonsi, B.B. Boren, D. Howard, M. Longair, L. Moretti, R. Orlowski: Acoustic and audience response analyses of eleven Venetian Churches. Acoustics in Practice 1, 1 (2013) 39-52.

25. B.B. Boren, G. Caro, D. Calixto, J. González, V. Mendoza, F. Salazar, P. Padilla, G. Perez, A. Ramos, A. Rivera, R. Tapia, C. Paz, J. Zamudio: Mexico City's cathedral: An archaeoacoustical and musicological analysis, in Proceedings of the 22nd International Congress on Acoustics, Buenos Aires, Argentina. 2016.

26. G. Iannace: The use of historical courtyards for musical performances. Building Acoustics 23, 3-4 (2016) 207-222.

27. B.F.G. Katz, S. Leconte, E.V.A.A. Peter Stitt: A platform for experimental virtual archeological-acoustics to study the influence of performance space, in International Symposium on Room Acoustics (ISRA), Amsterdam, The Netherlands, 2019.

28. B.F.G. Katz, E.A. Wetherill: Fogg Art Museum Lecture Room, a calibrated recreation of the birthplace of room acoustics, in Forum Acusticum. 2005, pp. 2191-2196.

29. F. Martellotta, E. Cirillo, A. Carbonari, P. Ricciardi: Guidelines for acoustical measurements in churches. Applied Acoustics 70, 2 (2009) 378-388.

30. Rindel J.H.: Roman theatres and revival of their acoustics in the ERATO project. Acta Acustica United with Acustica 99 (2013) 21-29.

31. S. Weinzierl, P. Sanvito, F. Schultz, C. Buttner: The acoustics of renaissance theatres in Italy. Acta Acustica United with Acustica 101 (2015) 632-641.

32. A. Gaio: La chiesa degli Incurabili: Una macchina per la musica, in Architettura e Musica Nella Venezia Del Rinascimento, Howard D, Moretti L, Editors, Bruno Mondadori. 2006, pp. 353-364.

33. B.B. Boren, M. Longair: A method for acoustic modeling of past soundscapes, in Proceedings of the Acoustics of Ancient Theatres Conference, Patras, Greece. 2011.

34. M. Lopez: Objective evaluation of a simulation of the acoustics of a medieval urban space used for dramatic performances. Applied Acoustics 88 (2015) 38-43.

35. F. Martellotta, D. Preziuso, E. Cirillo, S.D. Crociata, E. Gasparini: Acoustical reconstruction of San Petronio Basilica in Bologna during the Baroque period: The effect of festive decorations, in Acoustics '08, Paris, France. 2008.

36. B.N.J. Postma, S. Dubouilh, B.F.G. Katz: An archeoacoustic study of the history of the Palais du Trocadero (1878-1937). Journal of the Acoustical Society of America 145, 4 (2019) 2810-2821.

37. B.N.J. Postma, B.F.G. Katz: Creation and calibration method of acoustical models for historic virtual reality auralizations. Virtual Reality 19, 3-4 (2015) 161-180.

38. B.N.J. Postma, D. Poirier-Quinot, J. Meyer, B.F.G. Katz: Virtual reality performance auralization in a calibrated model of Notre-Dame Cathedral, in EuroRegio2016, Porto, Portugal. 2016.

39. B.-I. Dalenbäck: Engineering principles and techniques in room acoustics prediction, in Baltic-Nordic Acoustics Meeting, Bergen, Norway. 2010. 
40. M. Vorlander: International round robin on room acoustical computer simulations, in 15th International Congress on Acoustics, Trondheim. 1995.

41. R.A. Leaver: Performing Bach: One or Many? The Choral Scholar 1, 1 (2009) 6-15.

42. B. Jerold: Performance conditions, standards and Bach's chorus. The Musical Times 158, 1941 (2017) 55-70.

43. H.T. David, A. Mendel, C. Wolff, Editors: The New Bach Reader. W. W. Norton and Company, New York and London, 1998.

44. C.S. Terry: Bach: A Biography. Oxford University Press, London, New York, Toronto, 1928.

45. C. Wolff: Building and construction history, in St. Thomas Church in Leipzig, Taddiken B, Editor, Evangelische Verlagsanstalt, Leipzig, Germany. 2017, pp. 5-14.

46. M. Petzoldt: St. Thomas Zu Leipzig. Evangelische Verlagsanstalt, Leipzig, Germany, 2000.

47. H. Stiehl: Das Innere der Thomaskirche zur Amtszeit Johann Sebastian Bach. Beiträge zur Bachforschung 3 (1984).

48. H. Magirius, H. Mai, T. Trajkovits, W. Werner, Editors: Stadt Leipzig Die Sakralbauten. Kunstverlag GmbH, Munich and Berlin, 1995.

49. T. Kevorkian: The Reception of the Cantata during Leipzig Church Services, 1700-1750. Early Music 30, 1 (2002) 26-44.

50. C.S. Terry: Bach's music and church acoustics. The Consort 2 (1931) 2-3.

51. J.E. Gardiner: Bach: Music in the Castle of Heaven. Alfred A. Knopf, New York, NY, 2013.

52. C. Wolff: Johann Sebastian Bach: The Learned Musician. W. W. Norton and Company, New York, NY, 2000.

53. T. Fischinger, K. Frieler, J. Louhivuori: Influence of virtual room acoustics on choir singing. Psychomusicology: Music, Mind, and Brain 25, 3 (2015) 208-218.

54. K. Kato, K. Ueno, K. Kawai: Effect of room acoustics on musicians' performance. Part II: Audio analysis of the variations in performed sound signals. Acta Acustica United with Acustica 101 (2015) 743-759.

55. K.J. Snyder: Tradition with variations: Chorale setting per omnes versus by Buxtehude and Bach, in Music and Theology: Essays in Honor of Robin A. Leaver, Chapter 3, Zager D, Editor, Scarecrow Press, Plymouth, UK. 2007, pp. 31-50.

56. A. Farina: Simultaneous measurement of impulse response and distortion with a Swept-Sine technique, in Proceedings of the 108th Audio Engineering Society Convention, Paris. 2000.

57. B.-I. Dalenbäck: Room acoustic prediction based on a unified treatment of diffuse and specular reflection. Journal of the Acoustical Society of America 1002 (1996) 899-909.

58. B.-I. Dalenbäck: CATT-Acoustic v9. CATT, Gothenburg, Sweden, 2011.

59. B.N.J. Postma, B.F.G. Katz: Perceptive and objective evaluation of calibrated room acoustic simulation auralizations. Journal of the Acoustical Society of America 140 (2016) 4326-4337.

60. L. Keibs, W. Kuhl: Zur Akustik der Thomaskirche in Leipzig. Acustica 9 (1959) 365-370.

61. F. Martellotta: the just noticeable difference of center time and clarity index in large reverberant spaces. Journal of the Acoustical Society of America 128, 2 (2010) 654-663.

62. B.-I. Dalenbäck: Whitepaper: What is Geometrical Acoustics (GA)? Technical report, CATT, Gothenburg, Sweden, 2018.

63. B.B. Boren, D. Abraham, R. Naressi, E. Grzyb, B. Lane, D. Merceruio: Acoustic simulation of Bach's performing forces in the Thomaskirche, in 1st EAA Spatial Audio Signal Processing Symposium, Paris, France. 2019.

64. B.B. Boren, M. Longair: Acoustic simulation of the church of San Francesco della Vigna, in Proceedings of Meetings on Acoustics: 164th Meeting of the Acoustical Society of America, 18 p. 2012.

65. D. Howard, L. Moretti: Sound and Space in Renaissance Venice. Yale University Press, New Haven and London, 2010.

66. B.B. Boren, M. Longair, R. Orlowski: Acoustic simulation of Renaissance Venetian Churches. Acoustics in Practice 1, 2 (2013) 17-28.

67. R.A. Leaver, J. Sebastian: Bach: Theological musician and musical theologian. Bach 31, 1 (2000) 17-33.

68. L.W. Spitz: The Protestant Reformation. Harper and Row, New York, 1985.

69. J.Y. Jeon, I.H. Hwang, Y.H. Kim: Investigation of the acoustical characteristics of organ pipes in a performing space. Building and Environment 77, June 2019 (2014) 50-60.

70. D.A. Bies, C.H. Hansen: Sound absorption in enclosures. Encyclopedia of Acoustics 3 (1997) 1115-1128.

71. L. Karlen: Akustik i rum och byggnader. Svensk Byggtjanst, 1983. 